\title{
Representações sociais de pais sobre atuação de homens como educadores de crianças de $0-3$ anos
}

\section{Social representations of parents on the role of men as educators of Children aged 0-3 years}

\section{Representaciones sociales de padres sobre actuación de los hombres como educadores de niños de 0-3 años}

\author{
Josiane Peres Gonçalves' \\ Adriana Horta de Faria" \\ 'Universidade Federal de Mato Grosso do Sul (UFMS), Naviraí, Mato Grosso do Sul - Brasil. E-mail: \\ josiane.peres@ufms.br \\ "Universidade Federal de Mato Grosso do Sul (UFMS), Naviraí, Mato Grosso do Sul - Brasil. E-mail: \\ adrianahortadefariafaria@yahoo.com.br
}

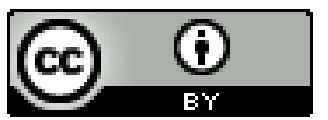

Educação: teoria e prática, Rio Claro, SP, Brasil - eISSN: 1981-8106

Está licenciada sob Licença Creative Common

\section{Resumo}

Este estudo busca investigar as representações sociais dos pais e das mães de crianças matriculadas em turmas da Educação Infantil, com idade entre de 0-3 anos, sobre a atuação de homens como professores nessa etapa da Educação Básica. A abordagem teórica baseia-se em pensadores como: Scott (1998), que conceitua gênero como uma questão cultural; Louro (2012), que aborda sobre a profissão docente que passou a ser vista como feminina; Moscovici (1973), que afirma que as pessoas têm as suas atitudes baseadas nos valores e nas ideias predominantes na sociedade, entre outros. Foram feitas entrevistas semiestruturadas, gravadas em áudio, que, posteriormente, foram transcritas e analisadas, com duas mães e dois pais de crianças com idade entre 0-3 anos, matriculadas em instituições de Ensino Infantil, na cidade de Naviraí-MS. Os resultados indicam que as representações sociais predominantes são de que a função do professor da Educação Infantil está intrinsecamente relacionada ao papel maternal e que há o receio de abuso sexual quando se trata de homem atuando com 
crianças dessa faixa de idade. Percebe-se que o professor da Educação Infantil é visto pelos entrevistados mais como um cuidador de crianças do que como um professor educador.

Palavras-chave: Representações Sociais; Educação Infantil; Pais; Homens Professores.

\begin{abstract}
This study investigates the social representations of fathers and mothers of children enrolled in the kindergarten, aged 0-3 years, on the role of men as teachers in this stage of education. The theoretical approach is based on thinkers such as Scott (1998), which conceptualizes gender as a cultural issue; Blonde (2012), which discusses about the teaching profession that came to be seen as feminine; Moscovici (1973), which states that people have their attitudes based on the values and ideas prevalent in society, among others. Semi-structured interviews were conducted and recorded in audio, which were transcribed and analyzed later, with two mothers and two fathers of children aged 0-3 years who were enrolled in institutions of Infant Education in the city of Navirai, MS. The results indicate that social representations are prevalent that the role of Professor of Early Childhood Education is intrinsically related to the maternal role and there is the fear of sexual abuse when it comes to men working with children of this age. It is noticed that the teacher of Infant Education is seen by most respondents more as a caregiver for children than as a teacher educator.
\end{abstract}

Keywords: Social Representations; Infant Education; Parent; Men Teachers.

\title{
Resumen
}

Este estudio busca investigar las representaciones sociales de los padres y de las madres de niños matriculados en grupos de Educación Infantil, con edad entre 0-3 años, sobre la actuación de hombres como profesores en esta etapa de la Educación Básica. El abordaje teórico se basa en pensadores como: Scott (1998), que conceptúa género como una cuestión cultural; Louro (2012), que aborda la profesión docente que pasó a ser vista como femenina; Moscovici (1973), que afirma que las personas tienen sus aptitudes basadas en los valores y en las ideas predominantes en la sociedad, entre otros. Se hicieron entrevistas semiestructuradas, grabadas en audio, con dos madres y dos padres de niños con edad entre 0-3 años, matriculadas en instituciones de Enseñanza Infantil, en la ciudad de Naviraí-MS que, posteriormente, se transcribieron y fueron analizadas. Los resultados indican que las representaciones sociales predominantes son aquellas en las que la función del profesor de la Educación Infantil está intrínsecamente relacionada al papel maternal y que hay el recelo de abuso sexual cuando se trata de un hombre actuando con niños de esa franja de edad. Se percibe que el profesor de la Educación Infantil es visto por los entrevistados más como un cuidador de niños que como un profesor educador.

Palabras clave: Representaciones Sociales; Educación Infantil; Padres; Hombres Profesores. 


\section{Introdução}

O presente trabalho surgiu a partir de um resumo, apresentado em forma de pôster, em um evento internacional na área de gênero e, por tratar-se de um resumo, não foi possível explorar os relatos dos participantes da pesquisa, surgindo a necessidade de elaborar um artigo completo para aprofundar a abordagem teórica e apresentar os referidos resultados.

Vale ressaltar que este estudo faz parte de uma pesquisa que se encontra em andamento, em que se busca investigar sobre as representações sociais das famílias, gestores das escolas e docentes do gênero masculino sobre a atuação de homens professores com crianças.

Sabe-se que em níveis mais elevados de ensino é comum a presença de homens trabalhando como docentes, mas na Educação Infantil é praticamente inexistente, especialmente em turmas de 0 a 3 anos, em que as práticas relativas ao cuidar são mais frequentes, devido às características da faixa etária. Mas por que isso acontece? E o que pensam as famílias sobre ter um homem trabalhando na Educação Infantil com turmas de 0 a 3 anos? Quais são as representações sociais predominantes dos pais ou responsáveis por essas crianças?

Diante da problemática apresentada, a pesquisa, que tem por objetivo investigar as representações sociais dos pais e das mães de crianças matriculadas em turmas da Educação Infantil, com idade entre de 0-3 anos, sobre a atuação de homens como professores nessa etapa da Educação Básica, justifica-se como relevante por haver poucos estudos nessa área, especialmente voltados para a referida faixa etária.

Assim, buscou-se verificar se haveria alguma estranheza, por parte das famílias, quanto à presença de um professor homem atuando com crianças pequenas, se há alguma restrição aos cuidados físicos necessários a cada criança e se o fato de o gênero masculino ser considerado bruto comprometeria a respectiva atuação profissional.

A pesquisa de campo foi realizada pela utilização de entrevistas semiestruturadas, gravadas em áudio e, depois, transcritas e analisadas, com dois pais e duas mães de crianças na faixa etária de 0-3 anos, matriculadas na rede municipal de Ensino Infantil na cidade de Naviraí-MS. Os resultados da pesquisa bibliográfica e de campo são apresentados na sequência.

\section{Por que os homens se afastaram da educação escolar de crianças?}

Historicamente, homens e mulheres desempenhavam papéis sociais distintos. Cabia à mulher ocupar-se das tarefas domésticas e da educação dos filhos, enquanto os homens deveriam trabalhar para prover o sustento da família. Dessa forma é que se estabelecia o papel que cada sexo deveria executar na sociedade. Desde a colonização do Brasil, são notórias as 
diferenças na prática social, econômica, política e educacional entre os dois sexos. Segundo Caetano e Neves (2013), a questão de gênero é a maneira assumida de diferenciar homens e mulheres.

Quanto se fala em gênero, é relevante analisar o conceito considerado por Scott (1998, p. 15):

Gênero é a organização social da diferença sexual. Ele não reflete a realidade biológica primeira, mas ele constrói o sentido desta realidade. A diferença sexual não é a causa originária da qual a organização social poderia derivar; ela é, antes, uma estrutura social móvel que deve ser analisada nos seus diferentes contextos históricos.

Assim, entende-se por sexo a diferença biológica existente entre homem e mulher, enquanto gênero, por sua vez, é uma construção social e histórica que fundamenta a distinção e a relação entre o feminino e o masculino. Nesse sentido, Gonçalves $(2009$, p. 26) afirma que “[...] o sexo se refere às diferenças biológicas de homens e mulheres, enquanto que gênero é um construto social relacionado à forma como historicamente os grupos sociais foram criando e efetivando os padrões de comportamentos para ambos os sexos".

As relações de gênero na educação escolar brasileira inicialmente eram bem diferentes, visto que somente homens atuavam como professores. Posteriormente, contudo, em decorrência de acontecimentos sociais nos séculos XIX e XX, como a revolução industrial, por exemplo, as mulheres começaram a participar de forma ativa na sociedade (além dos limites do lar) e a ocupar alguns postos que, anteriormente, eram exclusivos dos homens. A profissão docente foi uma das primeiras e principais ocupações da mulher naquele período.

De acordo com Caetano e Neves (2013), no final do século XIX o regime monárquico brasileiro entrou em declínio, e foi proclamada uma nova organização sociopolítica, a chamada república. Há, então, uma preponderância do discurso liberal e, em 1891, aprovou-se a primeira Constituição republicana, que defendia, em linhas gerais, que o Brasil tinha o dever de construir, por meio de adoção de ensino público e do fortalecimento da sociedade civil, um novo tipo de brasileiro. Esse novo cidadão deveria estar preparado para o trabalho livre e atender aos ideais republicanos. Em razão disso, atribuiu-se à educação um papel central na vida nacional, o papel de promover a modernização do país, ou seja, primeiramente combater o analfabetismo, pois, à época, o índice de analfabetismo era considerável (a maioria da população era analfabeta).

Diante desse contexto, Nogueira e Schelbauer (2013) comentam que, para reverter o analfabetismo, era necessária a criação de novas escolas, ou seja, aumentando a demanda de mão de obra docente. A partir dessa necessidade, foi oportunizado espaço para a mulher se inserir no mercado de trabalho como educadora. Nesse sentido, Hypólito (1997) destaca que a 
feminização do magistério foi parte fundamental e que ocorreu por diversos fatores, como se pode perceber, e não somente pelo fator econômico.

Essas mulheres obtinham a sua formação profissional na chamada Escola Normal, tipo de escola que, apesar de existir desde meados do século XIX, foi efetivamente sendo disseminado no período republicano, e com a tarefa de formar os professores primários. Essa formação era de nível secundário, ou seja, inicialmente era algo elementar, com noções gerais de Língua Portuguesa (incluindo Caligrafia e Gramática), de Matemática, de Geografia, de Lógica, de Doutrina Religiosa, entre outras disciplinas. Gradativamente, foram incluídas no currículo das escolas normais noções de psicologia, de medicina, de biologia (ciências naturais) e, também, de ciências sociais (CAETANO; NEVES, 2013).

Os professores formados em escola normal eram vistos como verdadeiros regeneradores da pátria, pois pautavam a prática no que existia de mais moderno no processo pedagógico. Esses docentes eram, também, os depositários de uma série de valores morais que a República exaltava, como honestidade, laboriosidade e patriotismo. Esses estabelecimentos de ensino estavam ligados à apropriação feminina dos espaços públicos, espaços inicialmente ocupados por homens, mas que acabaram se tornando predominantemente espaços femininos. Eis, pois, que é no grupo escolar republicano que se inicia a feminização do magistério, momento em que meninos e meninas passaram a ocupar a mesma instituição, ainda que em salas e com currículos diferentes.

Cabe informar, contudo, que essa conquista não aconteceu sem turbulência. Nogueira e Schelbauer (2013) consideram que os positivistas ressaltavam que as mulheres eram inferiores biológica e intelectualmente em relação ao homem, não sendo capazes de assumir alguma posição pública na sociedade. Em oposição, os que advogavam em favor da permanência das mulheres professoras usavam como argumento o instinto maternal, considerando como nato o papel de educadora. Para Louro (2012), a inserção das mulheres como professoras no mercado de trabalho passou a ser vista como uma extensão da maternidade:

\begin{abstract}
Afirmavam que as mulheres tinham, "por natureza", uma inclinação para o trato com as crianças, que elas são as primeiras e "naturais educadoras". Portanto nada mais adequado do que lhes confiar a educação dos pequenos. Se o destino primordial da mulher era a maternidade bastaria pensar que o magistério representava, de certa forma, uma "extensão da maternidade", cada aluno ou aluna vistos como filho ou filha "espiritual" (LOURO, 2012, p. 450 , grifos do autor).
\end{abstract}

Nessa perspectiva, para exercer o papel docente, consideravam que a mulher estava preparada, pois já possuía o dom de cuidar, tarefa que ela já executava em seu lar. Sob essa ótica, Gonçalves (2009, p. 38) analisa: 
Dessa forma, os alunos e as alunas deveriam ser vistos como filhos e filhas e a profissão docente não subverteria a função feminina, podendo, ao contrário, ampliá-la ou sublimá-la. O magistério deveria ser entendido pelas mulheres como uma atividade de amor, de entrega e de doação, e, para isso, era fundamental ter a vocação para ensinar.

Pode-se relacionar a entrada da mulher no exercício do magistério ao fato de possuir características tipicamente femininas, como: bondade, compaixão, gentileza, paciência, entre outras. Para Louro (2012), essas características articulavam a tradição religiosa com a atividade docente, pois a figura feminina estava ligada aos ideais da moralidade cristã, em que a mulher era valorizada pelos papéis de mãe e de esposa. Trata-se de representações sociais que contribuíram para o afastamento dos homens do magistério e para aumento da participação feminina no ambiente escolar.

As representações sociais são conceituadas, segundo Moscovici (1973, p. 17), da seguinte forma:

[...] um sistema de valores, ideias e prática com uma dupla função: primeiramente, estabelecer uma ordem que habilitará os indivíduos a orientarem-se em seu mundo material e social e dominarem-no; e, em segundo lugar, possibilitar a realização da comunicação entre os membros de uma comunidade pelo fornecimento de um código para o "intercâmbio" social e de um código para nomearem e classificarem, sem ambiguidades, os diversos aspectos de seu mundo e de sua história individual e em grupo.

Pode-se entender que, segundo o referido autor, as representações sociais são vistas como um conjunto de conceitos e de explicações da vida cotidiana. As representações da família na educação são parte fundamental, pois a família tem interesse imediato e mediato na formação de seus filhos. Melo (2011, p. 165) sustenta que "Os pais e/ou familiares e responsáveis pelos estudantes compõem o quinhão da comunidade escolar”.

$\mathrm{Na}$ Educação Infantil, a representação social vigente é a predominância de mulheres atuando como professoras nessa faixa de ensino, pórem Ramos (2011) destaca que a presença masculina no ambiente escolar é vista como necessária e positiva ao desenvolvimento emocional da criança.

Tiriba (2005), em sua pesquisa para tese de doutorado sobre Crianças, natureza e educação infantil, afirma que, na área educacional, o cuidar está historicamente relacionado à assistência ao corpo. A educação de crianças de 0-5 anos, principalmente, exige cuidados específicos, por sua dependência física em relação aos adultos. É importante observar que as Diretrizes Curriculares Nacionais para a Educação Infantil (BRASIL, 2010, p. 19) afirmam que se deve proporcionar às crianças "A educação em sua integralidade, entendendo o 
cuidado como algo indissociável ao processo educativo". Por esse prisma, o cuidado físico da criança, que inclui a higiene pessoal, é parte integrante do sistema educacional para a infância.

Vale ressaltar que a Lei Federal no. 9.394, de 20 de dezembro de 1996 (BRASIL, 1996), que estabelece as Diretrizes e Bases da Educação Nacional, afirma que a Educação Infantil deve ser oferecida em duas etapas, sendo a primeira para crianças de 0 a 3 anos de idade (realizada em creches ou instituições equivalentes) e a segunda para crianças entre 4 a 6 anos de idade (realizada em pré-escolas). Ocorreu, contudo, que a redação da lei foi alterada em $2006^{1}$, passando a ser obrigatória a matrícula das crianças no ensino fundamental a partir dos 6 anos de idade. Em decorrência dessa alteração, a segunda etapa da Educação Infantil deve atender, então, crianças de 4 a 5 anos de idade.

Nas duas etapas, a finalidade da Educação Infantil é o desenvolvimento integral da criança, em seus aspectos físico, psicológico, intelectual e social, complementando a ação da família e da comunidade.

Nesse sentido, a educação de crianças nos Anos Iniciais divide a atuação do professor em duas partes, quais sejam: a de educar, considerada a principal função do professor, e a de cuidar, que inclui dar banho, trocar fraldas, ninar e alimentar, que são cuidados inevitáveis pelo estado de dependência da criança nessa idade. Entende-se, pois, que, nessa etapa da Educação Infantil, a presença da mulher seja majoritária, reforçando o que Louro (2012, p. 448) afirma, de que "[...] a mulher, ao atuar como professora, tem sua função relacionada ao cuidado e ao apoio maternal, o que contribuiu para a feminização do magistério".

É possível notar que a presença de homens atuando nessa etapa da educação escolar é cada vez mais escassa e, nesse sentido, Araújo e Hammes (2012, p. 7) explicam que:

[...] essa ausência ligada ao receio ou medo em relação à pedofilia, ao homossexualismo, a visão de que cuidar de crianças é uma tarefa exclusivamente feminina ou questiona-se se a educação de crianças realmente necessita de homens ou para eles existem outras profissões.

Ocorre, contudo, que as representações sociais quanto ao papel da mulher e do homem na sociedade têm sido revolucionadas, visto que mulheres executam papéis antes atribuídos aos homens, exercendo os mais diversos tipos de trabalho, e também porque, por outro lado, homens, atualmente, fazem tarefas antes consideradas femininas, como as tarefas domésticas, incluindo o cuidar das crianças. Assim, a estrutura social tem sido modificada, o que exige uma flexibilidade entre os seus membros:

\footnotetext{
${ }^{1}$ Lei Federal no 11.274/2006: Altera a redação dos arts. 29, 30, 32 e 87 da Lei Federal no 9.394, de 20 de dezembro de 1996, que estabelece as diretrizes e bases da educação nacional, dispondo sobre a duração de 9 (nove) anos para o ensino fundamental, com matrícula obrigatória a partir dos 6 (seis) anos de idade.
} 
Ainda que articuladas às mudanças sociais, as relações entre homens e mulheres são pautadas por valores e concepções culturais que se vinculam aos papéis sociais historicamente atribuídos ao masculino e ao feminino. É importante destacar que esses papéis se alteraram significativamente nos últimos tempos (RAMOS, 2011, p. 101).

Diante do que foi exposto através da abordagem teórica acima, é possível afirmar que houve uma mudança quanto à igualdade dos papéis masculino e feminino na família e que, entretanto, na área da educação escolar, isSo não ocorreu. Observa-se, no entanto, uma sutil manifestação de homens atuando como professores no Ensino Infantil. Pesquisa realizada pelo INEP, em 2007, constatou que dentre o total de 336.186 docentes que atuavam na educação infantil no Brasil, apenas 3,4\% eram professores do sexo masculino, e, de acordo com o Censo Escolar de 2011, os professores homens nessa etapa da educação consistiam em 2,9\%. Assim, diante dessa rara presença de homens atuando no Ensino Infantil, cabe questionar: $\mathrm{O}$ que pensam as famílias sobre essa possibilidade? A coleta de dados, cuja metodologia explicamos na sequência, busca refletir sobre as representações predominantes na concepção de pais e de mães de crianças de Educação Infantil.

\section{Metodologia}

Este trabalho consiste numa pesquisa de natureza qualitativa, tipo de pesquisa que, de acordo com Minayo (1998), é entendida como aquela capaz de incorporar as questões de significado e de intencionalidade como inseparáveis dos atos, das relações e das estruturas sociais. Buscou-se investigar as representações sociais da família - visto que essas representações são, efetivamente, parte integrante no processo escolar - diante da presença de homens atuando como professores de crianças na Educação Infantil. Assim, procurou-se entrevistar pais de crianças com idade entre 0 a 3 anos, que estivessem regulamente matriculados em instituições públicas de Educação Infantil.

Primeiramente, para fazer um breve levantamento do contexto social dos sujeitos da pesquisa, solicitou-se que o familiar informasse o grau de parentesco com a criança, sua idade e escolaridade, e a idade, o sexo e a etapa de ensino que a criança se encontrava. Após, questionou-se sobre a visão desse responsável sobre a possível presença de homens atuando na educação infantil. Também foi perguntado se os responsáveis pelas crianças teriam preferência por uma professora ou um professor.

Foi, então, com base nesses questionamentos acima que foram realizadas entrevistas (do tipo semiestruturadas), oferecendo liberdade para as respostas dos entrevistados. Segundo Lüdke e André (1986, p. 34), esse modelo de pesquisa, a partir de entrevistas semiestruturadas, "[...] permite a captação imediata e corrente da informação desejada, praticamente com qualquer tipo de informante e sobre os mais variados tópicos". 
As entrevistas foram gravadas em áudio, em seguida foram transcritas e, posteriormente, foi feita a leitura/escuta para todos os integrantes do GEPDGE. Para Spink (1995, p. 102), “[...] nessa etapa, é necessário ficar atento às características do discurso: a variação (versões contraditórias); os detalhes sutis, como silêncios, hesitações, lapsos (investimento afetivo presente); retórica, ou organização do discurso de modo a argumentar contra ou a favor de uma versão dos fatos".

Para facilitar a identificação dos sujeitos pesquisados, suas características, sua relação com a criança, sexo, idade e etapa de ensino em que as crianças se encontravam, foi elaborado o quadro abaixo. Para a preservação da identidade dos entrevistados e das crianças pelas quais são responsáveis, os nomes dos familiares foram codificados.

\section{Quadro 1 - Perfil dos Entrevistados}

\begin{tabular}{|c|c|c|c|c|c|c|}
\hline Sujeitos & $\begin{array}{l}\text { Relação parental com a } \\
\text { criança e configuração } \\
\text { familiar (quem mora na } \\
\text { mesma casa) }\end{array}$ & $\begin{array}{l}\text { Idade } \\
\text { em } \\
\text { anos }\end{array}$ & $\begin{array}{c}\text { Escolaridade e } \\
\text { Profissão/Ocupação } \\
\text { (do responsável) }\end{array}$ & $\begin{array}{l}\text { Sexo da } \\
\text { criança }\end{array}$ & $\begin{array}{l}\text { Idade } \\
\text { da } \\
\text { criança }\end{array}$ & $\begin{array}{c}\text { Etapa da } \\
\text { Educação } \\
\text { Infantil, } \\
\text { que a } \\
\text { criança se } \\
\text { encontra }\end{array}$ \\
\hline \multirow[t]{2}{*}{ Mãe 1} & - Mãe. & \multirow[t]{2}{*}{32} & $\begin{array}{l}\text { - Estudante de } \\
\text { Pedagogia }\end{array}$ & \multirow[t]{2}{*}{ Menino } & \multirow[t]{2}{*}{2 anos } & \multirow[t]{2}{*}{ Maternal II } \\
\hline & - Pai, mãe e dois filhos. & & - Secretaria. & & & \\
\hline \multirow[t]{2}{*}{ Pai 1} & - Pai. & \multirow[t]{2}{*}{37} & $\begin{array}{l}\text { - Ensino fundamental } \\
\text { incompleto. }\end{array}$ & \multirow[t]{2}{*}{ Menino } & \multirow[t]{2}{*}{2 anos } & \multirow[t]{2}{*}{ Maternal II } \\
\hline & - Pai, mãe e dois filhos. & & -Comerciante. & & & \\
\hline \multirow[t]{2}{*}{ Mãe 2} & - Mãe. & \multirow[t]{2}{*}{37} & $\begin{array}{l}\text { - Estudante de } \\
\text { Pedagogia. }\end{array}$ & Menina & 2 anos & Maternal II \\
\hline & - Pai, mãe e duas filhas. & & & & & \\
\hline \multirow[t]{2}{*}{ Pai 2} & - Pai. & \multirow[t]{2}{*}{42} & $\begin{array}{l}\text { - Ensino médio } \\
\text { completo. }\end{array}$ & \multirow[t]{2}{*}{ Menina } & \multirow[t]{2}{*}{2 anos } & \multirow[t]{2}{*}{ Maternal II } \\
\hline & - Pai, Mãe e duas filhas. & & - Vendedor. & & & \\
\hline
\end{tabular}

Fonte: Autoras (2015).

\section{Resultados e Discussão}

$\mathrm{Na}$ entrevista realizada para a obtenção de dados para esta pesquisa, a Mãe 1, estudante de Pedagogia, tinha um menino com 2 anos de idade frequentando uma creche pública em Naviraí. Ao ser questionada sobre o momento de matricular o seu filho na creche, se pudesse escolher, qual seria sua preferência entre um professor homem ou uma professora mulher para atuar com seu filho, afirmou: 
Eu acho que tanto um, como o outro, pode desenvolver um trabalho bom e pode passar aquilo que ele sabe para o meu filho. Às vezes o homem poderia até ser melhor que a mulher [...] o homem também tem capacidade, porque o mesmo tanto que a mulher estudou, ele também estudou. Aí no decorrer do tempo eu ia ver, né, a apresentação dele, como ele ia se portar... Se eu achasse que ele não fosse uma boa pessoa, né, capacitada pra tá ali com o meu filho, eu trocaria ele de escola ou mesmo de professor (MÃE 1).

Observa-se que a mãe, talvez por cursar Pedagogia, atribui maior valor à formação profissional e não ao gênero, e isso é muito interessante, porque realmente homens e mulheres que passaram por um curso de graduação que forma para ser professores, são considerados profissionais da educação, independentemente do gênero. Por outro lado, a mãe que, aparentemente, não tem nenhum tipo de preconceito, disse que ficaria atenta para ver as atitudes, e se achasse que ele (professor) não estava capacitado, mudaria o filho de escola ou de professor. É interessante que ela não faz o mesmo comentário em relação às professoras mulheres.

A segunda mãe, que tinha uma filha de 2 anos e meio matriculada na creche, ao opinar sobre a preferência por um homem ou por uma mulher como educador/a trabalhando com sua filha, disse: "[...] eu optaria pela mulher, porque assim sendo na creche eu acredito que a mulher tem mais jeito para lidar com a criança” (MÃE 2).

O Pai 1, que tinha um filho com 2 anos de idade, respondeu da seguinte forma à mesma pergunta: "Não teria muita preferência, não, porque, depende muito do ensinamento, acredito que tanto o homem quanto a mulher teriam a mesma capacidade de passar a educação para uma criança $[\ldots] ”$..

O Pai 2, que tinha uma filha com 2 anos de idade matriculada na Educação Infantil, deixa claro que:

[...] optaria pela professora, vamos dizer assim, a mulher explica mais, é mais compreensiva com as crianças. A mulher sabe cuidar mais que o homem, assim, mesmo que não seja filho dela, mas ela tem um mais carinho do que o homem [...] então na hora do banho uma brincadeira eu acho que a mulher é mais paciente, tem mais paciência que o homem (PAI 2).

Por esses relatos é possível perceber que os primeiros pais aceitariam um homem como professor de seus filhos, por considerarem que o homem é tão capaz quanto a mulher de educar as crianças. Mesmo assim, contudo, a Mãe 1 deixa claro que haveria uma vigilância quanto ao trabalho do professor homem e este teria que provar a sua capacidade.

A Mãe 2 e o Pai 2 têm preferência pela mulher atuando com crianças. Suas falas remetem ao que Louro (2012, p. 450) afirma sobre as representações sociais relativas à 
feminilização do magistério, representações que estão intrinsecamente ligadas a "[...] uma atividade de amor, de entrega e doação". Fica evidenciado que, para esses pais, pelo fato de ser do sexo feminino, a profissional já estaria preparada ou teria melhor desempenho do que o homem na mesma tarefa.

A Mãe 1, quando questionada sobre a sua opinião a respeito de professores homens atuando na Educação Infantil, com crianças na faixa etária de 0-3 anos, respondeu:

Bom, é, nós sabemos que na creche na idade do Rafael (2 anos) entra muito o cuidado, não seria só o ensinar.... é, e aí eu acho que ele não se sairia tão bem o homem nesta parte. A mulher tem mais cuidado com o filho sabe? [...] Apesar de que na faculdade eles vão fazer estágio, né, têm uma preparação, mas ia ser esquisito para lidar com crianças nesta faixa etária [...] (MÃE 1).

$\mathrm{Na}$ fala de alguns entrevistados, percebe-se que as representações sociais predominantes em relação ao trabalho docente com crianças pequenas estão intrinsecamente ligadas ao instinto maternal, sendo tomado como um pré-requisito para o desempenho das atividades educacionais com as crianças. Diferentemente das representações evidenciadas, Ramos (2011) baseia-se em Badinter (1985) para afirmar que existe um essencialismo exacerbado do amor materno:

[...] ao contestar ao mesmo tempo o "caráter inato" do sentimento materno e o fato de que ele seja partilhado por todas as mulheres. [...] o amor materno existe, sim, desde a origem dos tempos, mas não existe em todas as mulheres. Dessa forma, qualquer pessoa que não seja a mãe (o pai, a ama, etc.) pode "maternar" uma criança. [...] não é somente o amor materno que leva uma mulher a cumprir seus deveres maternais (RAMOS, 2011, p. 105).

Para o autor, nem todas as mulheres possuem o amor materno. Em razão disso, independentemente do sexo, qualquer pessoa pode ser capaz de educar e/ou cuidar de crianças. Destaca, ainda, que os homens, ao contrário do que muitos pensam, sabem cuidar e educar crianças.

Sobre a atuação de homens como professores na Educação Infantil com as crianças de 0-3 anos, a Mãe 2 fala:

Eu acho interessante, mas na pré-escola, na creche, eu acho assim que é meio complicado para um professor do sexo masculino tá lidando com a criança na creche, porque na creche, é o berçário e o maternal... Então no berçário tem o banho, tem o contato, a trocação de fralda, o colocar pra dormir; então na creche é muito o cuidar, claro que tem o educar, mas muito 
é o cuidar. Então eu acredito que o professor do sexo masculino é mais interessante na pré-escola, é onde a criança já consegue ir ao banheiro sozinha e o professor vai ter então mais a parte do educar, vai ter o cuidar, mas é menos, né... (MÃE 2).

Fica evidente, nas representações sociais dos pais, a separação do binômio cuidar e educar, principalmente com as crianças pequenas, porém, na Educação Infantil, estes são fatores humanos indissociáveis. Nota-se que, para a entrevistada, o professor pode realizar as tarefas ligadas à educação, mas não as relacionadas com o cuidado físico.

O Pai 2 expressa o seguinte a respeito da educação ministrada por homens para as crianças do maternal e da creche:

Eu não concordo, não acho uma boa ideia, não acho mesmo uma boa ideia, basicamente porque a mulher tem mais paciência, até porque a educação infantil é isso aí, né, mais brincar, banho, brincadeira... Não é uma coisa mais avançada como em outro grau de escolaridade, num $5^{\circ}$ ano, sem ser educação infantil. Fora da educação infantil já é diferente, já não são mais crianças, aí eu concordo, não tem problema nenhum (PAI 2).

É notório, para o entrevistado, que o cuidado/educação das crianças é função feminina. Nesse sentido, Gonçalves (2009) analisa: “[...] as representações sociais inerentes à profissão docente continuam associando o magistério como sendo uma extensão da maternidade, como se fosse algo natural e próprio do universo feminino".

Durante a entrevista, a Mãe 2 afirmou que ficaria ressabiada com a presença de um professor do sexo masculino em uma instituição de Ensino Infantil. Quando questionada sobre o motivo que a levaria a ter esse medo, respondeu:

Por ser um homem, entendeu, para lidar com a criança na creche, então a gente não tem assim o conhecimento de professores que trabalham na creche. Então assim a gente fica em dúvida porque não conhece o trabalho, a gente não sabe como vai ser. E a gente sabe que a mulher já tem mais aquele dom de mãe, né, a mulher já pega mais, como se diz, o jeito para lidar com a criança, né, desta idade, porque depende de bastante cuidado, né, esta idade assim até 3 ou 4 anos [...], é o banho, é o trocar. Então, a mulher, a gente a vê mais bem preparada para isso, apesar de que o pai sempre faz isso. Aqui em casa mesmo, meu marido sempre deu banho, sempre trocou fralda, mas uma outra pessoa, um homem que a gente nem conhece, é meio complicado, né (MÃE 2). 
Fica claro que a entrevistada tem receio quanto ao homem atuando na Educação Infantil e que esse receio é devido à necessidade dos cuidados físicos com a criança. Cruz (1998, p.244) sustenta que se encontra, tanto na creche quanto no âmbito familiar, um medo relacionado à concepção da sexualidade masculina como algo incontrolável. Em muitas falas dos entrevistados, às vezes, explícito, outras vezes, velado, encontra-se um medo vinculado à pedofilia. Então, se torna evidente que, para os pais, existe uma relação entre o cuidar e os impulsos sexuais masculinos.

Nesse sentido, Ramos (2011) afirma que o cuidado físico executado por parte dos educadores/cuidadores homens representa, para os pais, uma ameaça à integridade física da criança e que a mesma representação não é atribuída aos profissionais do sexo feminino:

Eles explicitam que, nas ações do cuidar, há restrição apenas para os homens, pois as professoras não representam nenhum tipo de ameaça para as crianças na medida em que trazem consigo a vocação para a maternidade e elas são, por natureza, quem protege e cuida dos filhos com desvelo e são incapazes de cometer maldade contra crianças (RAMOS, 2011, p. 107).

A Mãe 2 destaca, contudo, que “[...] existindo mais o professor na Educação Infantil, a gente iria começar a ver como é o trabalho dele e o fato de começar a observar, a sociedade em geral vai começar a aceitar e vai começar a ter mais uma aceitação pela sociedade". Ou seja, a situação de homens atuando com crianças, fato que inicialmente causa estranheza, pode, com o aumento da presença masculina nessa etapa de ensino, vir a ter a aprovação da comunidade escolar.

\section{Considerações Finais}

Considerando que o objetivo do presente estudo foi verificar as representações sociais de pais de crianças pequenas quanto a homens trabalhando na fase inicial de educação escolar, pode-se afirmar que é possível constatar que os pais entrevistados relacionam a educação escolar das crianças pequenas com a função materna e consideram que as mulheres têm, inata, a capacidade de cuidar de crianças, enquanto os homens são considerados brutos, sem paciência ou sem jeito para lidar com os pequenos.

Os entrevistados acreditam que causaria estranheza a presença de um homem no ambiente escolar infantil, pois só encontram mulheres atuando com crianças na faixa etária de 0-3 anos, e que, diante de um professor do sexo masculino, os pais ficariam espantados. Três pais se posicionaram contra a ideia de homens executando atividades relacionadas ao cuidado físico das crianças, e o fizeram de forma explícita, demonstrando receio da pedofilia. Entendem que, sob os cuidados de uma mulher, seus filhos estão protegidos dessa ameaça. Assim, os professores do sexo masculino podem executar tarefas ligadas à educação, mas não devem ser, de forma alguma, relacionadas ao cuidado físico das crianças. 
É possível perceber que, de acordo com as representações sociais, o fator do instinto materno, um dos motivos que alguns teóricos afirmam levar à feminização do magistério, é visto como requisito para o trabalho com as crianças, o que nos remete à tradição assistencialista da educação infantil, onde a creche serve de substituição dos cuidados da mãe.

Fica evidente que causaria estranheza um homem atuando como professor, e que existe uma preferência pela mulher atuando com as crianças nessa etapa da educação. Isso pode ocorrer pelo fato de os responsáveis estarem acostumados à grande presença feminina nas salas de aula de educação infantil, o que lhes é familiar. Assim, diante da possibilidade de um homem professor, fica claro que existe uma resistência à presença de homens na creche.

Quanto ao binômio educar e cuidar, essas atividades são, nas representações sociais dos pais, aspectos distintos. Segundo essas representações, o educar é entendido como a escolarização e pode ser feito por homens. Assim, educar é muito diferente de cuidar, que envolve serviços como dar banho e trocar fraldas, serviços que, se executados por homens, seriam inquietadores para os pais, seja por inabilidade desses professores homens, seja até por maior probabilidade de pedofilia.

Os entrevistados, de forma velada, demonstram acreditar que o homem não seria capaz de controlar seus impulsos sexuais diante do toque físico necessário ao cuidado. Ao declararem que não seria apropriado que um homem executasse tarefas como dar banho e trocar fraldas, os entrevistados evidenciam um receio da pedofilia, tratando de forma separada o princípio indissociável da educação infantil de educar e cuidar.

A docência, de atuação exclusiva de homens há alguns séculos, passou a ser uma profissão de predominância feminina, principalmente na Educação Infantil. Dada essa transformação, atualmente os entrevistados vêem com estranheza, e até lhes causa receio, a presença de um professor do sexo masculino lidando com as crianças pequenas na instituição de ensino.

É importante ressaltar que a educação infantil adquiriu cunho educativo, reconhecendo a criança como cidadão que precisa ter desenvolvidos os seus aspectos fisiológicos, psicológicos, intelectuais, afetivos e socioculturais. As crianças necessitam ter convívio com adultos, que são as suas referências, de ambos os sexos, especialmente na escola, local em que elas iniciam a socialização fora da família.

Diante dos resultados, sugerem-se novas pesquisas com famílias que tenham professores homens atuando com crianças em instituições de educação infantil, em outros municípios, visto que no município em que a pesquisa foi realizada não foi encontrado esse sujeito. Entende-se que é importante fazer um comparativo entre as representações sociais apresentadas neste trabalho com as de famílias que presenciam o trabalho de homens com essa etapa da educação, para verificar as relações entre seus resultados. 


\section{Referências}

ARAÚJO, P. M.; HAMMES. C. C. A androfobia na educação infantil. Interfaces da Educação, Paranaíba, v. 3, n. 7, p. 5-20. 2012. Disponivel em: <periodicos.uems.br/novo/ index.php/interfaces/article/download/.../1150>. Acesso em: 14 jul. 2013.

BADINTER, Elisabeth. Um amor conquistado: o mito do amor materno. Rio de Janeiro: Nova Fronteira, 1985.

BRASIL. MEC. Lei n. 9.394 de 20 de dezembro de 1996. Estabelece as Diretrizes e Bases da Educação Nacional. Brasília: MEC, 1996.

BRASIL. MEC. Lei n ${ }^{\circ} 11.274$. Dispõe sobre a duração de 9 (nove) anos para o ensino fundamental. Diário Oficial da União, Brasília, Sessão 1, página 1. De 06 de fevereiro de 2006.

BRASIL. Instituto Nacional de Pesquisas Educacionais Anísio Teixeira. Censo dos Profissionais do Magistério da Educação Básica. Brasília: INEP, 2007.

BRASIL. MEC. Secretaria de Educação Básica. Diretrizes Curriculares Nacionais para a Educação Infantil. Brasília: MEC/SEB, 2010.

BRASIL. Instituto Nacional de Pesquisas Educacionais Anísio Teixeira. Censo dos Profissionais do Magistério da Educação Básica. Brasília: INEP, 2011.

CAETANO, E.; NEVES, P. E. C. Feminização do magistério: algumas questões. VIII Seminário Nacional de Estudos e Pesquisas: História, Sociedade e Educação no Brasil, Campinas, 2009. Anais do VIII Seminário Nacional de Estudos e Pesquisas: História, Sociedade e Educação no Brasil. Campinas: UNICAMP, 2009. Disponível em: <http://www.histedbr.fe.unicamp.br/acer_histedbr/seminario/seminario8/trabalhos.html>. Acesso em: 26 jul. 2013.

CRUZ, E. F. "Quem leva o nenê e a bolsa?": o masculino na creche. In: ARILHA, M.; RIDENTI, S. G. U.; MEDRADO, B. (Orgs.). Homens e masculinidades: outras palavras. São Paulo: ECOS/Ed. 34, 1998, p. 235-255.

GONÇALVES, J. P. O perfil profissional e representações de bem-estar docente e gênero em homens que tiveram carreiras bem-sucedidas no magistério. 2009. 232 f. Tese (Doutorado em Educação) - Pontifícia Universidade Católica do Rio Grande do Sul, Porto Alegre, 2009.

HYPÓLITO, A. L. M. Trabalho docente, classe social e relações de gênero. Campinas: Papirus, 1997. (Coleção Magistério, Formação e Trabalho Pedagógico). 
LOURO, G. L. Mulheres na Sala de Aula. In: PRIORE. M. D.; PINSK. B. C. (Orgs.). História das mulheres no Brasil. São Paulo: Contexto, 2012, p.441-481.

LÜDKE, M.; ANDRÉ, M. E. D. A. Pesquisa em educação: abordagens qualitativas. São Paulo: EPU, 1986.

MELO, A. Relações entre a comunidade e a escola. Curitiba: Ibpex, 2011.

MINAYO, M. C. S. Pesquisa social: teoria, método e criatividade. Petrópolis: Vozes, 1998.

MOSCOVICI, S. A social psychological analysis. London: Academic Press, 1973.

NOGUEIRA, K. J.; SHELBALUER, R. A. Feminização do magistério no Brasil: o que relatam os pareceres do Primeiro Congresso da Instrução do Rio de Janeiro. VII Jornada do HISTEDBR: O trabalho didático na história da educação, Campinas, 2007. Anais do VII HISTEDBR. Campinas: UNICAMP, 2007. Disponível em:

<http://www.histedbr.fae.unicamp.br/acer_histedbr/jornada/jornada7/_GT1\%20PDF/FEMINI ZA\%C7\%C3O\%20DO\%20MAGIST\%C9RIO\%20NO\%20BRASIL.pdf>. Acesso em: 22 jul. 2013.

RAMOS, J. Um estudo sobre os professores homens da educação infantil e as relações de gênero na Rede Municipal de Belo Horizonte - MG. 2011. 139 f. Tese (Doutorado em Educação) - Pontifícia Universidade Católica de Minas Gerais, 2011. Disponível em: <http://www.biblioteca.pucminas.br/teses/Educacao_RamosJ_1.pdf >. Acesso em: 15 jul. 2013.

SCOTT, J. Gênero: uma categoria útil de análise histórica. Educação e realidade, Porto Alegre, v. 2, n. 20, p. 71-99, Jul./Dez. 1998.

SPINK, M. J. P. O estudo empírico das representações sociais. In: (Org.). $\mathbf{O}$ conhecimento no cotidiano: as representações sociais na perspectiva da psicologia social. São Paulo: Brasiliense, 1995, p. 85-108.

TIRIBA, L. Crianças, natureza e educação infantil. 2005. 249 f. Tese (Doutorado em Educação) - Pontifícia Universidade Católica do Rio de Janeiro, Rio de Janeiro, 2005.

Recebido em: 30/10/2013

Revisado em: 16/03/2015

Aprovado para publicação em: 26/03/2015

Publicado em: 31/08/2015 